Special Issue of the 6th International Congress \& Exhibition (APMAS2016), Maslak, Istanbul, Turkey, June 1-3, 2016

\title{
Effect of Two-Step Oxidation on Performance of Micro-Arc Oxidation on 6063 Aluminum Alloy
}

\begin{abstract}
A. AYDAY*
Sakarya University, Faculty of Engineering, Department of Metallurgical and Materials Engineering, Sakarya, 54187, Turkey

This paper investigates the effect of different electrolytes containing silicate and phosphate by two-step oxidation using the micro-arc oxidation technique. The growth effect, surface roughness, and element distributions of the micro-arc oxidation coatings were characterized. The composition of coating was characterized using X-ray diffraction and energy dispersive spectrum, and the morphology was examined using scanning electron microscope. The surface characterizations results show that the coating growth forms are different in Si and $\mathrm{P}$ electrolytes while the coated samples were almost composed of $\gamma-\mathrm{Al}_{2} \mathrm{O}_{3}$.
\end{abstract}

DOI: 10.12693/APhysPolA.131.96

PACS/topics: $81.65 . \mathrm{Mq}, 68.37 . \mathrm{Hk}$

\section{Introduction}

Aluminum alloys have good properties, for example high strength, low density, non-magnetic properties, and good formability. But the poor surface hardness and wear resistance limited their application in many ways [1-3]. That is why some surface treatments are used to improve their mechanical properties. Micro arc oxidation (MAO) has been widely studied in recent years for preparing ceramic coatings on metals $(\mathrm{Al}, \mathrm{Mg}, \mathrm{Ti})$ to develop the surface behavior $[2,4]$. However, these coatings are usually coarse and porous, which reduces their tribological performance and corrosion resistance. Many researchers study the effect of electrical breakdown voltage, electrolyte composition, current density on the surface properties [3-5]. But some researchers study inward growth mechanism of MAO coatings. The morphology and properties of MAO coating are related to the growth mechanism, the investigation of growth mechanism is crucial to improve the performance of MAO coating [6].

However, our recent research shows that the influence of the electrolytes is significant not only on the coating properties but on the coating growth patterns. In this paper, the MAO process of $2 \mathrm{~A} 70$ aluminum alloy is investigated in the electrolytes containing silicate or phosphate by one-step and two-step oxidation. The coating growth patterns affected by the electrolyte are discussed in detail.

\section{Experimental}

The substrate material in the present study was 6063 aluminum alloy $(0.45 \%-0.90 \% \mathrm{Mg}, 0.35 \% \mathrm{Fe}, 0.2 \%-$ $0.6 \% \mathrm{Si}, 0.10 \% \mathrm{Cu}, 0.10 \% \mathrm{Mn}, 0.10 \% \mathrm{Cr}, 0.10 \% \mathrm{Zn}$, $0.10 \% \mathrm{Ti}$, and balance $\mathrm{Al}$, mass fraction) for $\mathrm{MAO}$ experiment.

\footnotetext{
*e-mail: aayday@sakarya.edu.tr
}

The MAO treatment was carried out using a pulsed AC power source in alkaline silicate, phosphate electrolyte, respectively. Three types of electrolytes were composed of $2.5 \% \mathrm{~g} / \mathrm{l} \mathrm{Na} 2 \mathrm{SiO}_{3}, 2.5 \% \mathrm{~g} / \mathrm{l} \mathrm{NaOH}$ (solution I) and $2.5 \% \mathrm{~g} / 1 \mathrm{Na}_{2} \mathrm{SiO}_{3}, 2.5 \% \mathrm{~g} / \mathrm{l} \mathrm{NaOH}, 2.5 \% \mathrm{~g} / 1 \mathrm{NaH}_{2} \mathrm{PO}_{2}$ (solution II) in distilled water, respectively. The two-step oxidation experiments were applied to prepare MAO coating with the same electrical parameters. In the first step, specimens were put into silicate electrolyte for $10 \mathrm{~min}$ oxidation. In the second step, specimens with preliminary MAO coatings were put into phosphate electrolyte and oxidized for different durations. The oxidation times in the second step were $2 \mathrm{~min}, 5 \mathrm{~min}$, and $10 \mathrm{~min}$, and the opposite were applied to the samples. The sample codes and parameters were given in Table I.

The surface morphologies of coatings were observed by scanning electron microscopy (SEM) and chemical composition of the MAO coatings was analyzed by energydispersive X-ray spectroscopy (EDS) incorporated into the scanning electron microscope. The phase composition of the MAO coatings was analyzed by using an X-ray diffractometer with $\mathrm{Cu} K_{\alpha}$ radiation at $40 \mathrm{kV}$ and $60 \mathrm{~mA}$ with a step size of $0.02^{\circ}$ at a scanning rate of $2^{\circ} /$ min over the $2 \theta$ range of $0^{\circ}$ and $90^{\circ}$.

Sample codes and parameters.

TABLE I

$\left.\begin{array}{c|c|r}\hline \hline \text { Code } & \text { Electrolytes } & \text { Treatment time [min] } \\ \hline \text { S } & \text { solution I } & 10 \\ \text { SP2 } & \text { solution I+solution II } & 10+2 \\ \text { SP5 } & \text { solution I+solution II } & 10+5 \\ \text { SP10 } & \text { solution I+solution II } & 10+10 \\ \text { P } & \text { solution II } & 10 \\ \text { PS2 } & \text { solution II+solution I } & 10+2 \\ \text { PS5 } & \text { solution II+solution I } & 10+5 \\ \text { PS10 } & \text { solution II+solution I } & 10+10\end{array}\right\}$ P group




\section{Results and discussion}

Figure 1 demonstrates the evolution of surface morphology of S groups (Fig. 1A-D) and P groups (Fig. 1E$\mathrm{H})$ micro-arc coatings. The $\mathrm{S}$ code sample prepared under silicate electrolytes without phosphate electrolyte (Fig. 1A) presented different images than SP10. The second step of $2 \mathrm{~min}$ (Fig. 1B), 5 min (Fig. 1C) and $10 \mathrm{~min}$ phosphate electrolyte coating on $\mathrm{S}$ code samples make small micropores and discharge channels and finally they were closed in Fig. 1D. On the other hand, the P code sample surface morphologies are different. The difference is the dimensions of the holes. Volcano-like structures can be found in Fig. 1A but Fig. 1B is like a pancake with small size discharge channels. After the following step coating $2 \mathrm{~min}$ (Fig. 1F), 5 min (Fig. 1G) and $10 \mathrm{~min}$ (Fig. $1 \mathrm{H}$ ) silicate electrolyte coating on $\mathrm{P}$ code samples there occur large channels.

Figure 2A,B represents the EDS map analyses of SP10 and PS10 coatings, respectively. It can be found that
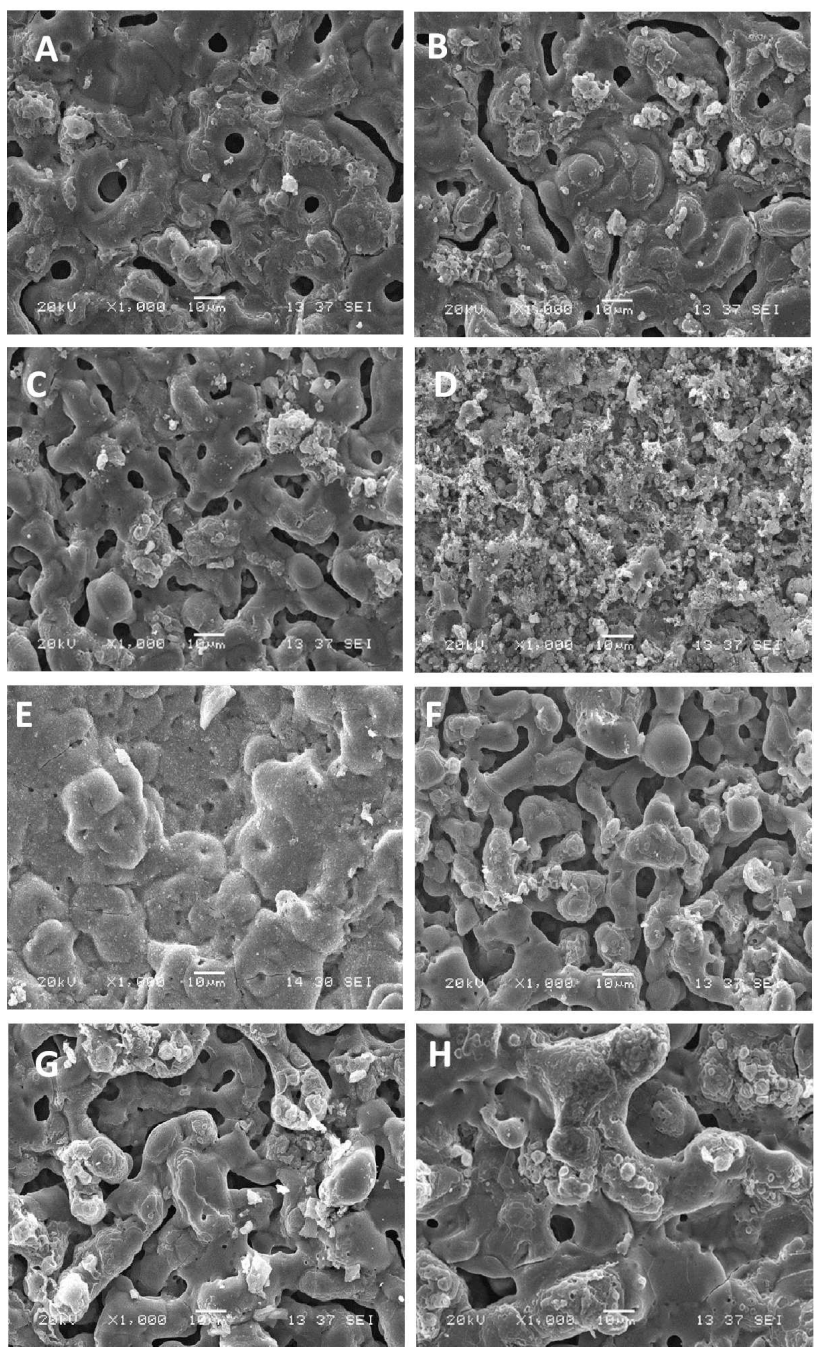

Fig. 1. SEM image of coating (A-D) S groups [(A) S, (B) SP2, (C) SP5, (D) SP10], (E-H) P groups [(E) P, (F) PS2, (G) PS5, (H) PS10].

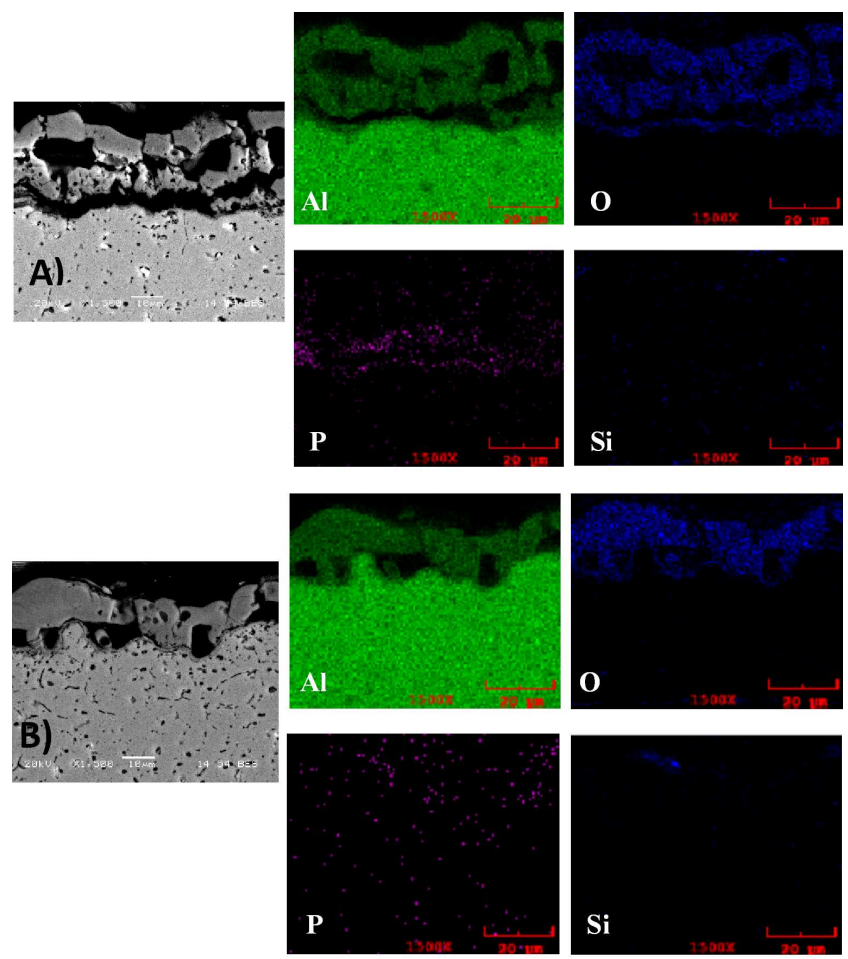

Fig. 2. EDS results of the MAO coatings prepared by two-step oxidation: (A) SP10, (B) PS10.



Fig. 3. XRD patterns of Al6063, PS10 and SP10 code samples.

the main elements $\mathrm{Al}$ and $\mathrm{O}$ existed in all coatings. $\mathrm{Si}$ in the coating formed in silicate electrolyte while $\mathrm{P}$ is the main element in the coating formed in phosphate electrolyte. So Si and $\mathrm{P}$ can be used to trace the growth process of the coatings formed in the two electrolytes. From Fig. 2A, though the phosphate base electrolyte was the second step coating, $\mathrm{P}$ element was detected below the coating layer. This shows that $\mathrm{P}$ element exists in electrolyte with the form of negatively charged partial phosphate ions, which makes it able to enter coating during discharging. SEM image and EDS results of PS10 firstly oxidized in P-electrolyte for $10 \mathrm{~min}$ and then further oxidized in Si-electrolyte for $10 \mathrm{~min}$ are presented in Fig. 2B. Some Si-rich areas can also be found far to the substrate, which indicates that the coating does not grow inward. Figure 3 shows the XRD patterns of MAO 
coatings formed silicate electrolyte and phosphate electrolyte. The coatings formed in two-step electrolytes are mainly composed of $\mathrm{Al}$ and $\gamma-\mathrm{Al}_{2} \mathrm{O}_{3}$.

\section{Conclusion}

The two-step oxidation method is shown to be beneficial for studying the MAO growth patterns. Silicate electrolyte and phosphate electrolyte coating have different discharge channels shapes, which can affect the oxidation reaction area during MAO process. The second step phosphate coatings on silicate layer realized to grow inward. Though phosphate base electrolyte was the second step coating, $\mathrm{P}$ element was detected in discharge channels. When the MAO coating is formed firstly in the phosphate electrolyte and then in the silicate electrolyte by the two-step method oxidation, no obvious inward growth layer can be observed. Oxide coatings $\left(\gamma-\mathrm{Al}_{2} \mathrm{O}_{3}\right.$ phase) were successfully formed on the surface of all parameters.

\section{References}

[1] Y. Yürektürk, F. Muhaffel, M. Baydoğan, Surf. Coat. Technol. 269, 83 (2015).

[2] M. Shokouhfar, S.R. Allahkaram, Surf. Coat. Technol. 291, 396 (2016).

[3] N. Xiang, R. Song, J. Zhao, H. Li, C. Wang, Z. Wang, Trans. Nonferrous Met. Soc. China 25, 3323 (2015).

[4] H. Li, R. Song, Z. Ji, Trans. Nonferrous Met. Soc. China 23, 406 (2013).

[5] D. Veys-Renaux, C.-E. Barchiche, E. Rocca, Surf. Coat. Technol. 251, 232 (2014).

[6] W. Li, Z. Qian, X. Liu, L. Zhu, H. Liu, Appl. Surf. Sci. 356, 581 (2015). 